Technological University Dublin

DÜBLIN

ARROW@TU Dublin

\title{
Investigation of a scalable barrel atmospheric plasma reactor for the treatment of polymer particles
}

\author{
Hisham Abourayana \\ University College Dublin \\ Vladimir Milosavljevic \\ Technological University Dublin, vladimir.milosavljevic@tudublin.ie \\ Peter Dobbyn \\ University College Dublin
}

See next page for additional authors

Follow this and additional works at: https://arrow.tudublin.ie/scschphyart

Part of the Physics Commons

\section{Recommended Citation}

Abourayana, Hisham \& Milosavljevic, Vladimir \& Dobbyn, Peter \& Cullen, P.J \& Dowling, Denis. (2016). Investigation of a Scalable Barrel Atmospheric Plasma Reactor for the Treatment of Polymer Particles. Surface and Coatings Technology. 308. 435 - 441. 10.1016/j.surfcoat.2016.06.094.

This Article is brought to you for free and open access by the School of Physics \& Clinical \& Optometric Science at ARROW@TU Dublin. It has been accepted for inclusion in Articles by an authorized administrator of ARROW@TU Dublin. For more information, please contact arrow.admin@tudublin.ie, aisling.coyne@tudublin.ie, gerard.connolly@tudublin.ie.

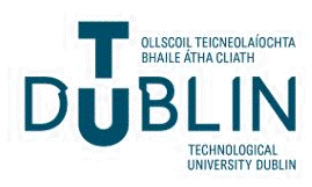




\section{Authors}

Hisham Abourayana, Vladimir Milosavljevic, Peter Dobbyn, Patrick J. Cullen, and Denis Dowling

This article is available at ARROW@TU Dublin: https://arrow.tudublin.ie/scschphyart/158 
See discussions, stats, and author profiles for this publication at: https://www.researchgate.net/publication/305922738

\section{Investigation of a Scalable Barrel Atmospheric Plasma Reactor for the Treatment of Polymer Particles}

Article in Surface and Coatings Technology · December 2016

DOI: 10.1016/j.surfcoat.2016.06.094

CITATIONS

12

5 authors, including:

Hisham M. Abourayana

University College Dublin

11 PUBLICATIONS 97 CITATIONS

SEE PROFILE

Peter Dobbyn

University College Dublin

11 PUBLICATIONS 66 CITATIONS

SEE PROFILE
D Vladimir Milosavljevic

University of Belgrade

121 PUBLICATIONS 1,726 CITATIONS

SEE PROFILE

P.J Cullen

The University of Sydney

362 PUBLICATIONS 15,277 CITATIONS

SEE PROFILE

Some of the authors of this publication are also working on these related projects:

Project Plasma sintering of nickel-diamond metal-matrix-composites (MMCs) View project

Project 3D Printing of Fibre Reinforced Composite Parts View project 
Investigation of a Scalable Barrel Atmospheric Plasma Reactor for the Treatment of Polymer Particles

Hisham M. Abourayana ${ }^{\mathrm{a}}$, Vladimir Milosavljević ${ }^{\mathrm{b}}$, Peter Dobbyn ${ }^{\mathrm{a}}$, Patrick J. Cullen ${ }^{\mathrm{b}}$ and Denis P. Dowling ${ }^{a^{*}}$

${ }^{\text {a }}$ Surface Engineering Group, School of Mechanical and Materials Engineering, University College Dublin, Belfield, Dublin 4, Ireland

${ }^{\mathrm{b}}$ BioPlasma Research Group, Dublin Institute of Technology, Dublin 1, Ireland

* Corresponding author. Tel.: +35317161747; Email address: denis.dowling@ucd.ie

\begin{abstract}
This study reports on the performance of a scalable barrel atmospheric plasma system for the treatment of polymer particles. A novel feature of the barrel system design is the use of a biased electrode, which also acts as the roller for the glass barrel. The plasma is generated using either helium or helium / oxygen gas mixtures. The reactor was used to activate $20 \mathrm{~g}$ batches of silicone, polypropylene (PP), acrylonitrile butadiene styrene (ABS) and polyethylene terephthalate (PET) particles, each with diameters in the range 3 to $5 \mathrm{~mm}$. The effect of plasma treatment time and gas flow rate on the water contact angle of the treated polymer particles was examined. The polymer water contact angles decreased from up to $140^{\circ}$ to less than $10^{\circ}$ after the barrel plasma treatment (polymer dependent). X-ray photoelectron spectroscopy (XPS) analysis is used to monitor the effect of the plasma treatment on both PET and silicone polymer particles. Optical emission spectroscopy (OES) was used as a diagnostic tool to monitor changes in atomic and molecular species intensity with experimental conditions. Emission lines of helium, oxygen and molecular bands of $\mathrm{OH}, \mathrm{N}_{2}$ and $\mathrm{N}_{2}{ }^{+}$were monitored and correlated with their spatial distribution within the plasma chamber. Electrical characterisation studies demonstrated an increase in plasma power with increasing input voltage and helium flow rate. The heating effect of the plasma was monitored using an infrared thermographic camera, the maximum barrel temperature after 30 minutes treatment found to be $29^{\circ} \mathrm{C}$. While the current barrel plasma system design can treat $20 \mathrm{~g}$ of polymer the system design has the potential to be readily scalable for the activation of larger batches of particles.
\end{abstract}

Keywords: Atmospheric pressure plasma, Polymer particle, Barrel reactor, Optical emission spectroscopy 


\section{Introduction}

Polymer powders find end use applications in products such as paint fillers, in biotechnology (cell supports) or as composite fillers materials [1]. Polymers, however typically exhibit low surface energies and hydrophobic properties [2]. Plasma treatments have been extensively applied as a means of enhancing polymer surface energy, through the introduction of polar groups and cross-linking on the surface, without changing the bulk composition [3]. These treatments are dry, clean, rapid and environment-friendly [4]. Plasmas also have the advantage of a very low specific consumption of chemicals and energy [5]. Both low pressure and atmospheric pressure discharges have been applied for these treatments [6]. Compared with low pressure sources, the advantages of an atmospheric pressure glow discharge is the elimination of the requirement for vacuum equipment, thus achieving reduced processing costs [7]. The industrial applications of plasma processing have however largely focused on flat polymer substrates [8]. Compared with flat surfaces, the treatment of polymer powders can give rise to handling issues associated with particle aggregation, difficulties in handling variations in particle size as well as the requirement for long treatment times due to the large surface area per unit mass [9]. This is reflected in the relatively few reports on the use of atmospheric pressure discharges for the activation of polymer powders in the literature [10]. Amongst the plasma reactor designs, plasma-fluidized bed reactors, plasma downer reactors and plasma batch reactors are reported [11-13]. Of these the most widely applied has been the fluidized bed system, however this source can have difficulties where there are a range of particle sizes being treated (difficulty in keeping larger particles suspended, while preventing loss of smaller particles) [14]. In the case of the barrel reactor, the particles are agitated in the discharge by the barrel's rotation. There have been very few reports on the performance of this reactor type for the treatment of particles at atmospheric pressure [15]. This paper evaluates a novel design of barrel plasma reactor where the electrodes and rollers are one end mounted around the barrel i.e., the biased and earthed electrodes are incorporated into the rollers that are used to rotate the reactor.

\section{Experimental}

The barrel reactor was designed and constructed as shown in Figure 1. It consists of a quartz chamber with dimensions of $15 \mathrm{~cm}$ length and $10 \mathrm{~cm}$ inner diameter. The chamber was sealed with two removable Teflon plugs which were inserted $2.5 \mathrm{~cm}$ into the chamber, thus the effective treatment length was $10 \mathrm{~cm}$. The plasma operated at a frequency of $20 \mathrm{kHz}$, an input voltage of up to $110 \mathrm{~V}$ with a maximum of $100 \mathrm{~W}$ output from the power supply (Plasma Technics Inc.). This equates to a $10 \mathrm{kV}$ high voltage output. The powder charge of $20 \mathrm{~g}$ was agitated by rotation of the glass chamber, with a speed of approximately 7 rotations per minute. Helium and helium / oxygen gas mixtures were investigated as the process gases. Their flow rate was controlled using rotameters (Bronkhorst). In this design the aluminum rods used to rotate the chamber also act as the biased and earthed electrodes. This arrangement is in-contrast to conventional designs in which the electrode and roller arrangement are kept separate. Amongst the potential advantages of the new design are firstly ease of barrel removal from the rollers (no electrodes preventing access). A further potential advantage is that the intimate contact between the roller and the glass should help to minimise ozone generation between the electrode and the glass of the barrel reactor.

A number of different process monitoring techniques were used to monitor the barrel reactor. Optical emission spectra were obtained using an Ocean Optics USB4000 UV/VIS spectrometer in the $200-850 \mathrm{~nm}$ region. This system has a resolution of approx. $1.2 \mathrm{~nm}$ full width at half maximum (FWHM). The OES lens was centrally placed underneath the chamber and light from the plasma passes through a focusing lens and along the 1 metre, $400 \mu \mathrm{m}$ multimode fiber optic cable. The OES technique is based on the integration of measured signals over a line-of-sight observation. Optical emission spectra were collected every $20 \mathrm{~s}$ for a total of 3 minutes using an integration time of $2 \mathrm{~s}$. The plasma chamber temperature was measured using a VarioCam high resolution infrared thermographic camera with resolution of $640 \times 480$ 
pixels. Thermal measurements were made after 30 minutes of plasma generation under a given processing condition. To provide an alternative method of temperature measurement of the discharge treated surface, thermocouple measurements (K-type) where performed on plasma chamber wall. The applied voltage was measured using a North Star PVM-5 high voltage probe with a ratio of $(1 \mathrm{~V}$ per $\mathrm{kV})$, which was directly connected to the electrodes of the plasma barrel. The current measurements were obtained with a Bergoz Instrumentation France, toroidal current transformer (CT-E5.0) with an output of $5 \mathrm{~V}$ per Ampere. The current and voltage waveforms were monitored using a 4 channel digitizer $(300 \mathrm{MHz}$ bandwidth) Oscilloscope (Techtronix). In this paper the RMS of the voltage and current waveforms were obtained over a time period of approximately $0.1 \mathrm{~ms}$. This procedure yields an estimation of the average AC power, namely $(\mathrm{P}=\mathrm{IV})$ of the non-sinusoidal waveforms according to equation 1 [16].

$$
\mathrm{P}(\mathrm{W})=\mathrm{V}_{\mathrm{rms}}(\text { Volt }) X \mathrm{I}_{\mathrm{rms}}(\text { Ampere }) \quad \text { Equation } 1
$$

The atmospheric plasma treatment of the following polymer particles was investigated: silicone, polyethylene terephthalate (PET), polypropylene (PP) and acrylonitrile butadiene styrene (ABS). The silicone polymer particles were manufactured from their resin (Wacker Elastosil). This involved firstly mixing the silicone rubber resin (LSR 3003/70) using the parts A \& B liquid precursors. The resulting polymer was then formed into $5.0 \mathrm{~mm}$ diameter cylindrical filaments using a screw extrusion process, it was then thermally cured at $155^{\circ} \mathrm{C}$. The extruded filament was mechanically cut using an automated blade cutting system, to obtain the required cylindrical polymer particle size of $5.0 \mathrm{~mm}$ diameter and $0.5 \mathrm{~mm}$ thick. The manufacturing procedure is described in detail elsewhere [17]. The PET was manufactured as a sheet material by Holfeld Plastics, Ireland and were then cut into particle samples with dimensions of approximately $3 \times 4 \times 0.35 \mathrm{~mm}$. The (PP) was manufactured by INEOS Olefins \& Polymer Europe and the (ABS) granules were obtained from LG Chem., both had particle sizes in the range of 3 to $4 \mathrm{~mm}$.

The wettability of the polymer particles was determined using water contact angle measurements (Dataphysics Instruments OCA 20, sessile droplet technique). Measurements were obtained using deionized water droplets of volume of $0.5 \mu \mathrm{l}$ at room temperature.

Polymer surface chemistry changes were monitored using X-ray photon electron spectroscopy (XPS) analysis (Kratos Analytical Axis Ultra system) set-up with a monochromated Al Ka Xray source. The $\mathrm{C} 1 \mathrm{~s}, \mathrm{O} 1 \mathrm{~s}$ peaks (for PET) and $\mathrm{C} 1 \mathrm{~s}, \mathrm{O} 1 \mathrm{~s}$ and $\mathrm{Si} 2 \mathrm{p}$ peaks (for silicone) were recorded along with 50-1,000 eV survey scans. The measurements were obtained within 2 hours of plasma activation of the polymers. The intensities of the peaks were determined as the integrated peak areas assuming the background to be linear.

\section{Results and discussion}

This section firstly considers the plasma and thermal diagnostics of the barrel source and then the evaluation of the barrel's effectiveness for the plasma activation of polymer particles.

\section{Electrical Characterisation}

These barrel plasma measurements were carried out using a North Star high voltage probe and a Bergoz Instrumentation current probe, connected to a digital oscilloscope (Techtronix). Under the treatment conditions of $10 \mathrm{slm}$ helium flow rate and $100 \mathrm{~V}$ operating voltage, the plasma was found to operate at a frequency of $\sim 20 \mathrm{kHz}$ and output voltage and current measurements of $19.2 \mathrm{kV}$ (peak-peak) and $20.6 \mathrm{~mA}$ respectively. The effect of input voltage on the plasma power was also investigated. The output power as expected, increased with increasing input voltage. The maximum output power obtained is $30 \mathrm{~W}$ at $100 \mathrm{~V}$.

The effect of both helium and oxygen flow rates on the plasma power were also investigated. It was found that the plasma power increased with increasing helium flow rate. A probable explanation for this is that as the helium flow rate increases, the ionisation and conductivity of 
the plasma also increase, leading to an increase in the amount of discharge per unit volume and thus the current and discharge power [18]. In contrast an increase in the oxygen flow rate leads to a decrease in the plasma power due to partial quenching (oxygen is an electronegative gas) [19]. Figure 2 shows the effect of both helium and oxygen flow rates on the barrel plasma power.

\section{Optical emission spectroscopy (OES) and thermal measurements}

OES was used to investigate plasma species as the helium and helium/oxygen flow rates and operating voltage were varied. A typical emission spectra of the helium plasma is shown in Figure 3. Its composition presents similar atomic and molecular spectral emissions to those previously reported [20]. The atomic helium spectral emission lines, atomic emission lines of oxygen and molecular bands of hydroxyl $(\mathrm{OH})$, Nitrogen $\left(\mathrm{N}_{2}\right)$ and $\mathrm{N}_{2}{ }^{+}$are presented in the radiation spectrum. For the pure helium discharge, the observation of emissions from $\mathrm{OH}, \mathrm{N}_{2}$ and $\mathrm{N}_{2}{ }^{+}$is induced mainly by the presence of air impurities in the helium gas stream from trapped ambient air [21].

At wavelengths both below and around $400 \mathrm{~nm}$, the emission of the second positive system of molecular nitrogen $\mathrm{N}_{2}\left[\mathrm{C}^{3} \Pi^{+}{ }_{\mathrm{u}}-\mathrm{B}^{3} \Pi_{\mathrm{g}}^{+}\right]$is observed [22]. The corresponding vibrational band heads, $v=0 \rightarrow 0,1,2,3$ are located at the wavelengths, $\lambda=337,358$ and 380 and $406 \mathrm{~nm}$, respectively. At $\lambda=391 \mathrm{~nm}$ the $v=0 \rightarrow 0$ band of the first negative system of molecular nitrogen ions $\mathrm{N}_{2}{ }^{+}\left[\mathrm{B}^{2} \Sigma^{+}{ }_{\mathrm{u}}-\mathrm{X}^{2} \Sigma^{+} \mathrm{g}\right]$ is observed. Two lines from atomic species are found in the near-infrared region: $\mathrm{He}\left[3 \mathrm{~s}^{3} \mathrm{~S}^{1}-2 \mathrm{p}^{3} \mathrm{P}^{0}\right]$ at $706 \mathrm{~nm}$ and $\mathrm{O}\left[3 \mathrm{p}^{5} \mathrm{P}-3 \mathrm{~s}^{5} \mathrm{~S}\right]$ at $777 \mathrm{~nm}$ [23]. While in the UV emission band, $\mathrm{OH}$ radicals $\mathrm{OH}\left[\mathrm{A}^{2} \Sigma^{+}-\mathrm{X}^{2} \Pi\right]$ around $307 \mathrm{~nm}$ are found as well as the $\gamma$-bands of nitrogen oxide $\mathrm{NO}\left[\mathrm{A}^{2} \Sigma_{\mathrm{u}}-\mathrm{X}^{2} \Pi\right]$ below $300 \mathrm{~nm}$.

The effect of the applied voltage and gas flow rate on the resulting intensity of the plasma species was also investigated. To provide an indication of the relative importance of specific species to plasma processing conditions, the spectral intensity of a number of the OES peaks were integrated. Six wavelengths were selected for this investigation; $307 \mathrm{~nm}(\mathrm{OH} 307), 337$ $\mathrm{nm}\left(\mathrm{N}_{2} 337\right), 391 \mathrm{~nm}\left(\mathrm{~N}_{2}+391\right), 706 \mathrm{~nm}$ (He706), $777 \mathrm{~nm}(\mathrm{O} 777)$ and $844 \mathrm{~nm}(\mathrm{O} 844)$. Note that the latter peak only appears with oxygen addition into the plasma. It was found that the total spectral intensity increased as expected with an increase in voltage. The most homogeneous plasma was formed using $100 \mathrm{~V}$ input voltage and a He flow rate of $10 \mathrm{slm}$. It was observed that increasing the oxygen flow rate leads to a decrease in the intensity of the oxygen peak at $777 \mathrm{~nm}$ and also a decrease in the intensities of the other peaks, due to nonradiative energy transfer among the active species [24]. The optical intensity gives an indication of the density (concentration) of the reactive species. From all the induced reactive species, oxygen is the most chemical active species. To establish an importance of each atoms/molecules in plasma, the "normalisation" of the emission spectrum versus the highly reactive species such as oxygen is conducted. A ratio between the recorded spectral intensities from the plasma and the $\mathrm{O} 777$ would indicate a level of plasma chemistry dilution by oxygen. Figure 4 shows the effect of the oxygen flow rate on the intensities of the plasma species. The normalisation process means calculating a ratio between the current spectral intensities of $\mathrm{OH} 307, \mathrm{~N}_{2} 337, \mathrm{~N}_{2}{ }^{+} 391, \mathrm{He} 706$ and the $\mathrm{O} 777$ spectral intensity for each gas mixture (i.e. the spectral intensity $\mathrm{O} 777$ acts as the denominator). The normalisation value provides a map of the plasma species' activities inside the barrel.

To gain an insight into plasma homogeneity, OES spectra were taken axially and radially. Figures 5 shows the axial and radial spectral emissions for the 5 most important emitters in this experiment. The experimental conditions used to obtain the OES data presented in these figures are a helium flow rate of $10 \mathrm{slm}$ and voltage of $100 \mathrm{~V}$. Oxygen in the experiment with pure helium $(*)$, comes from a trapped ambient air in the barrel and could be used as a benchmark (a minimum oxygen level in the barrel) for the other three experimental runs. The $\mathrm{O} 777$ and $\mathrm{N}_{2} 337$ spectral emissions show good homogeneity in both the radial and axial directions. Helium metastable atoms are very important for the creation of $\mathrm{N}_{2}^{+} 391$ emission, since the threshold for this process is over $18 \mathrm{eV}$ [24]. Therefore, $\mathrm{N}_{2}$ emission follows the 
same optical pattern as the He 706 emission. There is a similar situation with the $\mathrm{OH}$ spectral emission. The $\mathrm{OH}$ radicals could be produced through $\mathrm{H}_{2} \mathrm{O}$ dissociation or/and produced in the isothermal plasma gas flow (that includes trapped ambient gas atmosphere) by the reaction $\mathrm{H}+\mathrm{NO}_{2} \rightarrow \mathrm{NO}+\mathrm{OH}$, where $\mathrm{H}$ atoms are formed by the He plasma generated with low levels of contaminant humid air. The listed reaction with $\mathrm{NO}_{2}$ is most unlikely since the barrel design insures that the ambient air contribution to the plasma discharge is minimal as it is not an open space plasma discharge. This confined space plasma discharge contains a high helium concentration, which additionally limits the importance of the $\mathrm{NO}_{\mathrm{x}}$ species in the above reaction [24]. Since the dissociation of molecules $\left(\mathrm{H}_{2} \mathrm{O}\right)$ is most likely described by the gas kinetic temperature, the radical $\mathrm{OH}$ can be used as an indication of temperature in an ambient gas plasma discharge. From this study as shown in figure 10, the maximum intensity of $\mathrm{OH}$ occurs at the middle of the barrel. Just to stress that the spectral emissions presented in Figures 3 can only be used as a reference point for the reactive species concentration in the barrel and not as absolute concentration measurements.

For the thermal imaging analysis, the temperature of the glass chamber was recorded 30 minutes after the plasma was ignited. The maximum temperature obtained was $28.9^{\circ} \mathrm{C}$. The external temperature was further conformed using both infrared thermometer (accuracy \pm 2 ${ }^{\circ} \mathrm{C}$ ), with a laser pointer and a K-type thermocouple. Figure 6 shows a thermographic image of the plasma chamber, indicating the homogeneity of the temperature generated by the plasma. This homogeneity is enhanced due to chamber rotation.

\section{Barrel plasma treatment of polymer particles}

The effects of the $\mathrm{He} / \mathrm{O}_{2}$ barrel plasma treatment time on the water contact angle of the silicone, PP, ABS and PET polymer particles are shown in Figure 7. The behavior of the silicone is clearly different to that observed for the other polymers with a much more significant and gradual decrease in contact angle. This difference in behavior with this polymer is likely to be due to the strength of its $\mathrm{Si}-\mathrm{O}$ bond, which has higher bond energy than $\mathrm{C}-\mathrm{O}, \mathrm{C}-\mathrm{H}$ and $\mathrm{C}-\mathrm{N}$ bonds [25]. A further factor is that the silicone particles used in this study have a much rougher and more porous morphology, which is likely to significantly increase their surface area, compared with the other polymers investigated [17].

The effect of oxygen flow rate on the He plasma was also investigated. Its increase had a pronounced effect on the contact angle of the silicone polymer, but less so compared with the case of PP, ABS and PET. This lack of impact of oxygen addition particularly at higher concentrations may be associated with the partial quenching of the discharge with the addition of higher levels of oxygen and thus decreasing its ability to activate the polymer particles [26].

The effect of helium flow rate (from 2 to $10 \mathrm{slm}$ ) on the effectiveness of the barrel plasma discharge on activation of the polymers (based on water contact angle) was investigated. The silicone polymer was the only one of the four polymer particles investigated for which changes in He flow rate had an effect on polymer contact angle. It was found that the water contact angle decreased to less than $5^{\circ}$ with increased helium flow rate to $8 \mathrm{slm}$. For PP, ABS, and PET it was found that there is no significant effect of helium flow rate on the resultant polymer water contact angle of these polymers. Figure 8 shows the effect of both helium and oxygen flow rate on the water contact angle of the different polymers.

\section{XPS Analysis}

The surface chemistry changes associated with the plasma treatments of PET and silicone polymer particles was monitored by XPS. Table 1 shows the compositions of the PET polymers before and after plasma treatment. The $\mathrm{C}: \mathrm{O}$ ratio of the untreated PET was found to be 4.7. The theoretical atomic percentages of carbon to oxygen atoms based on repeat unit for untreated PET is 2.5. The difference between the observed C:O ratio and that of the repeat 
unit may be due to low levels of hydrocarbon contamination on the surface of the polymer particles [27]. After plasma treatment, the $\mathrm{C}: \mathrm{O}$ ratio drops to 1.8. The addition of oxygen to the helium plasma did not lead to a significant increase in the percentage of oxygen.

The C 1s spectra of PET before and after plasma treatment are shown in Figure 9. Each spectrum was deconvoluted into three peaks, which are assigned as follows: a peak at binding energy of $285 \mathrm{eV}$ which corresponds to $\mathrm{C}-\mathrm{C}$ and $\mathrm{C}-\mathrm{H}$ bond (carbon atoms in phenyl ring), a second peak at $286.7 \mathrm{eV}$ which corresponds to $\mathrm{C}-\mathrm{O}$ bond (methylene carbon atoms singly bonded to oxygen), and a third peak at $289 \mathrm{eV}$, which corresponds to $\mathrm{O}=\mathrm{C}-\mathrm{O}$ bond (ester carbon atoms) [28].

The $\mathrm{C} 1 \mathrm{~s}$ spectrum of a treated PET revealed the significant chemical changes produced by the treatment due to the formation of additional functional groups. The relative areas of these peaks are summarized in Table 2 . The results indicate that a decrease of intensity occurs for $\mathrm{C}-\mathrm{C} / \mathrm{C}-\mathrm{H}$ bonds $(285 \mathrm{eV})$ after plasma treatment, with an increase in the intensity of both $\mathrm{C}-$ $\mathrm{O}(286.7 \mathrm{eV})$ and $\mathrm{O}-\mathrm{C}=\mathrm{O}(289 \mathrm{eV})$ bonds after plasma treatment, similar to the observation of other authors [29].

XPS analysis was also carried out on untreated and plasma treated silicone particles. As demonstrated in Table 3 the atomic percentage of oxygen was observed to increase with the addition of oxygen into the helium plasma.

The XPS high-resolution spectra of the Si $2 p$ line for untreated and plasma treated silicone particles are shown in Figure 10. The binding energy of the Si 2p peak of the untreated sample is observed at approximately $102 \mathrm{eV}$, which is consistent with the reported values for silicone [30]. The Si 2p binding energy is shifted to 102.7 and 103.8 after $\mathrm{He}$ and $\mathrm{He} / \mathrm{O}_{2}$ plasma treatment respectively. This energy shift is too high to be assigned for organic silicone species and is more consistent with binding energies assigned to silica type surfaces [30]. This observation is consistent with reports in the literature that silicone polymers the most probable mechanism of surface modification involve an increase in the surface concentration of polar groups, i.e. replacement of methyl groups by a silica layer [31]. The increase in oxygen functionality for PET and silicone after plasma treatment correlates with the decrease in water contact angle.

For $\mathrm{PP}$, the large reduction in water contact angle is likely to be due to the formation of oxygen-containing functionalities, such as $\mathrm{C}-\mathrm{O}, \mathrm{O}-\mathrm{C}=\mathrm{O}, \mathrm{C}=\mathrm{O}$ and $\mathrm{COOH}$ [32]. While for $\mathrm{ABS}$, an increase in the wettability due to the creation of $\mathrm{C}-\mathrm{O}, \mathrm{C}-\mathrm{OH}$ and $\mathrm{R}-\mathrm{COO}^{-}$polar groups is reported [33].

\section{Conclusion}

This study investigates the performance of a novel barrel atmospheric plasma systems for the activation of four types of polymer particles, namely; silicone, PP, ABS and PET using a He and $\mathrm{He} / \mathrm{O}_{2}$ plasma. The influence of processing parameters including; plasma treatment time, addition of oxygen to the helium plasma and helium flow rate on the level of plasma surface activation, based on WCA measurements were investigated. For PP, ABS and PET a significant decrease in water contact angle was observed during the first five minutes of plasma treatment, however these polymers were not found to be significantly affected by longer treatment times or alterations in $\mathrm{He}$ gas flow rates. Addition of oxygen into the $\mathrm{He}$ plasma led as expected to a decrease in water contact angle associated with increased oxygen functionality on the polymer surfaces. The silicone particles were found to be much more sensitive to the treatment with water contact angles of $<5^{\circ}$ obtained. The more gradual decrease in contact angle with plasma treatment time for this polymer may be associated with the higher bond strength of Si-O compared with $\mathrm{C}-\mathrm{O}$.

Higher oxygen concentrations in the discharge (i.e. $>0.1 \mathrm{slm} \mathrm{O}_{2}$ in an 8-10 slm He plasma), led to a partial quenching of the discharge. OES analysis demonstrated an increase in atomic species intensities with increased applied voltage. Spectral intensity was found to increase near from the wall and at the middle along the plasma chamber. Thermal imaging analysis 
demonstrated the homogeneity of the heating produced by the plasma possibly due to the rotation of the chamber.

While the current barrel plasma system design can treat $20 \mathrm{~g}$ of polymer, the system design where the electrodes are incorporated into the roller mechanism facilitates ease of scale-up. The length of the rollers can easily be extended and system design facilitates ease of barrel removal from the rollers.

Acknowledgement - The authors would like to acknowledge the support of IComp for this research. V. Milosavljević is also grateful to the Ministry of Education and Science under grant No. OI1611027.

\section{References}

[1] M. Gilliam, S. Farhat, A. Zand, B. Stubbs, M. Magyar, G. Garner, Atmospheric plasma surface modification of PMMA and PP micro-particles, Plasma Process. Polym. 11 (2014) 1037-1043.

[2] K.G. Kostov, A.L.R. dos Santos, R.Y. Honda, P.A.P. Nascente, M.E. Kayama, M.A. Algatti, et al., Treatment of PET and PU polymers by atmospheric pressure plasma generated in dielectric barrier discharge in air, Surf. Coatings Technol. 204 (2010) 3064-3068.

[3] S. Yoshida, K. Hagiwara, T. Hasebe, A. Hotta, Surface modification of polymers by plasma treatments for the enhancement of biocompatibility and controlled drug release, Surf. Coatings Technol. 233 (2013) 99-107.

[4] T. Jacobs, N. De Geyter, R. Morent, S. Van Vlierberghe, P. Dubruel, C. Leys, Plasma modification of PET foils with different crystallinity, Surf. Coatings Technol. 205 (2011) S511-S515.

[5] D. Papakonstantinou, E. Amanatides, D. Mataras, V. Ioannidis, P. Nikolopoulos, Improved surface energy analysis for plasma treated PET films, Plasma Process. Polym. 4 (2007) 1057-1062.

[6] J. Píchal, J. Hladík, P. Špatenka, Atmospheric-air plasma surface modification of polyethylene powder, Plasma Process. Polym. 6 (2009) 148-153. doi:10.1002/ppap.200800080.

[7] C. Wang, G. Zhang, X. Wang, X. He, Surface modification of poly(ethylene terephthalate) (PET) by magnet enhanced dielectric barrier discharge air plasma, Surf. Coatings Technol. 205 (2011) 4993-4999.

[8] M. Quitzau, M. Wolter, V. Zaporojtchenko, H. Kersten, F. Faupel, Modification of polyethylene powder with an organic precursor in a spiral conveyor by hollow cathode glow discharge, Eur. Phys. J. D. 58 (2010) 305-310.

[9] H. Hunke, N. Soin, T. Shah, E. Kramer, A. Pascual, M. Karuna, et al., Low-pressure $\mathrm{H}_{2}, \mathrm{NH}_{3}$ microwave plasma treatment of polytetrafluoroethylene (PTFE) powders: chemical, thermal and wettability analysis, Materials (Basel). 8 (2015) 2258-2275.

[10] S. Put, C. Bertels, A. Vanhulsel, Atmospheric pressure plasma treatment of polymeric powders, Surf. Coatings Technol. 234 (2013) 76-81.

[11] C. Vivien, C. Wartelle, B. Mutel, J. Grimblot, Surface property modification of a polyethylene powder by coupling fluidized bed and far cold remote nitrogen plasma technologies, Surf. Interface Anal. 34 (2002) 575-579.

[12] C. Arpagaus, A. Sonnenfeld, P.R. von Rohr, A downer reactor for short-time plasma surface modification of polymer powders, Chem. Eng. Technol. 28 (2005) 87-94. 
[13] N. Patra, J. Hladik, M. Pavlatová, J. Militký, L. Martinová, Investigation of plasmainduced thermal, structural and wettability changes on low density polyethylene powder, Polym. Degrad. Stab. 98 (2013) 1489-1494.

[14] J. Kim, Y. Kim, H. Choi, Thermal characteristics of surface-crosslinked high density polyethylene beads as a thermal energy storage material, Korean J. Chem. Eng. 19 (2002) 632-637.

[15] S. Fang, Y. Meng, J. Shen, J. Cong, Surface treatment of polypropylene powders using a plasma reactor with a stirrer, Plasma Sci. Technol. 13 (2011) 217-222.

[16] C.E. Nwankire, V.J. Law, a. Nindrayog, B. Twomey, K. Niemi, V. Milosavljević, et al., Electrical, thermal and optical diagnostics of an atmospheric Plasma jet system, Plasma Chem. Plasma Process. 30 (2010) 537-552.

[17] H.M. Abourayana, J.N. Barry, P. Dobbyn, D.P. Dowling, Comparison between the performance of fluidized bed and barrel rectors for the plasma activation of polymer particles, J. Mineral Metal and Material Eng. (2015) 57-64.

[18] N. Jidenko, M. Petit, J.P. Borra, Electrical characterization of microdischarges produced by dielectric barrier discharge in dry air at atmospheric pressure, J. Phys. D. Appl. Phys. 39 (2006) 281-293.

[19] V. Milosavljević, M. Donegan, P.J. Cullen, D.P. Dowling, Diagnostics of an $\mathrm{O}_{2}-\mathrm{He}$ RF atmospheric plasma discharge by spectral emission, J. Phys. Society Japan. 014501 (2014) 1-8.

[20] V. Poenariu, M.R. Wertheimer, R. Bartnikas, Spectroscopic diagnostics of atmospheric pressure helium dielectric barrier discharges in divergent fields, Plasma Process. Polym. 3 (2006) 17-29.

[21] Q. Xiong, A.Y. Nikiforov, M.Á. González, C. Leys, X.P. Lu, Characterization of an atmospheric helium plasma jet by relative and absolute optical emission spectroscopy, Plasma Sources Sci. Technol. 22 (2013) 015011.

[22] J.J. Camacho, J.M.L. Poyato, L. Díaz, M. Santos, Optical emission studies of nitrogen plasma generated by IR $\mathrm{CO}_{2}$ laser pulses, J. Phys. B At. Mol. Opt. Phys. 40 (2007) 4573-4590.

[23] M. Thiyagarajan, A. Sarani, C. Nicula, Optical emission spectroscopic diagnostics of a non-thermal atmospheric pressure helium-oxygen plasma jet for biomedical applications, J. Appl. Phys. 113, 233302 (2013).

[24] P.J. Cullen, V. Milosavljević, Spectroscopic characterization of a radio-frequency argon plasma jet discharge in ambient air, Prog. Theor. Exp. Phys. 2015 (2015) 1-17.

[25] A. Colas, Silicones: preparation, properties and performances, Dow Corning, Life Sci. (2005) 14.

[26] D.P. Dowling, J. Tynan, P. Ward, A.M. Hynes, J. Cullen, G. Byrne, Atmospheric pressure plasma treatment of amorphous polyethylene terephthalate for enhanced heatsealing properties, Int. J. Adhes. Adhes. 35 (2012) 1-8.

[27] A. Vesel, M. Mozetic, A. Zalar, XPS study of oxygen plasma activated PET, Vacuum. 82 (2007) 248-251.

[28] E.G. Ii, M.D. Barankin, P.C. Guschl, R.F. Hicks, Remote atmospheric pressure plasma activation of the surfaces of polyethylene terephthalate and polyethylene naphthalate, Langmuir. 24(2008) 12636-12643. 
[29] N. De Geyter, R. Morent, C. Leys, L. Gengembre, E. Payen, Treatment of polymer films with a dielectric barrier discharge in air, helium and argon at medium pressure, Surf. Coatings Technol. 201 (2007) 7066-7075.

[30] I.F. Husen, C. Chan, Chemical structure modification of silicone surfaces by plasma immersion ion implantation, J. Materials Science Letters. 19 (2000) 1883-1885.

[31] R.L. Williams, D.J. Wilson, N.P. Rhodes, Stability of plasma-treated silicone rubber and its influence on the interfacial aspects of blood compatibility, Biomaterials. 25 (2004) 4659-4673.

[32] K. Navaneetha Pandiyaraj, V. Selvarajan, R.R. Deshmukh, C. Gao, Adhesive properties of polypropylene (PP) and polyethylene terephthalate (PET) film surfaces treated by DC glow discharge plasma, Vacuum. 83 (2008) 332-339.

[33] J. Abenojar, R. Torregrosa-Coque, M.A. Martinez, J.M. Martin-Martinez, Surface modifications of polycarbonate (PC) and acrylonitrile butadiene styrene (ABS) copolymer by treatment with atmospheric plasma, Surf. Coatings Technol. 203 (2009) 2173-2180. 


\section{List of tables}

Table $1 \quad$ Atomic $\%$ of species on PET particles surface before and after plasma treatment.

Table 2 Atomic $\%$ of species on PET particles surface before and after plasma treatment.

Table 3 Atomic $\%$ of species on silicone particles surface before and after plasma treatment.

Table 1 Atomic $\%$ of species on PET particles surface before and after plasma treatment

\begin{tabular}{lccc}
\hline & $\% \mathrm{C}$ & $\% \mathrm{O}$ & $\mathrm{C}: \mathrm{O}$ \\
\hline Untreated & 82.39 & 17.61 & 4.67 \\
He treated & 64.66 & 35.34 & 1.82 \\
He/O treated & 61.47 & 38.53 & 1.59 \\
\hline
\end{tabular}

Table 2 Atomic $\%$ of species on PET particles surface before and after plasma treatment

\begin{tabular}{lccc}
\hline & $\% \mathrm{CC} / \mathrm{CH}$ & $\% \mathrm{C}-\mathrm{O}$ & $\% \mathrm{O}-\mathrm{C}=\mathrm{O}$ \\
\hline Untreated & 67.82 & 20.68 & 12.03 \\
He treated & 51.39 & 32.09 & 16.53 \\
He/O treated & 52.84 & 29.66 & 17.50 \\
\hline
\end{tabular}

Table 3 Atomic $\%$ of species on silicone particles surface before and after plasma treatment

\begin{tabular}{lcccc}
\hline & $\mathrm{Si}$ & $\mathrm{C}$ & $\mathrm{O}$ & $\mathrm{C}: \mathrm{O}$ \\
\hline Untreated & 21.50 & 53.75 & 24.75 & 2.17 \\
He treated & 23.45 & 33.83 & 42.73 & 0.79 \\
He/O treated & 24.55 & 23.15 & 52.30 & 0.44 \\
\hline
\end{tabular}




\section{List of figures}

Figure 1 Photograph of the barrel reactor (left) and schematic diagram of the plasma barrel showing a roller arrangement in direct contact with the barrel (right).

Figure 2 Effect of both helium flow rate (left) and oxygen flow rate (right) on the barrel plasma power.

Figure 3 Optical emission spectrum obtained from the barrel reactor.

Figure 4 Effect of oxygen flow rate on the plasma species intensities obtained by OES. (He flow rate $10 \mathrm{slm}$ and voltage $100 \mathrm{~V}$ ).

Figure 5 Axial (left) and radial (right) OES spectral distribution within the barrel chamber.

Figure 6 Thermographic image (He flow rate $10 \mathrm{slm}$ and input voltage $100 \mathrm{~V}$ ), the maximum temperature obtained was $28.9^{\circ} \mathrm{C}$.

Figure 7 Effect of plasma treatment time on the water contact angle of polymers. Note that for water contact angles of $<5^{\circ}$ no error bars are included, as it is not possible to obtain accurate angle measurements. (Input voltage $100 \mathrm{~V}, \mathrm{He}$ flow rate $10 \mathrm{slm}$ and $\mathrm{O}_{2}$ flow rate $0.05 \mathrm{slm}$ ).

Figure 8 Effect of helium flow rate (left) and oxygen flow rate (right) on the water contact angle of the different polymer particles. (Input voltage $100 \mathrm{~V}$ and activation time $30 \mathrm{~min}$ ). Note that in the case of oxygen flow rate the 0 point is for treatment in a He only plasma. While in the case of He flow rate graph the 0 point is the WCA obtained before plasma treatment.

Figure 9 C1s XPS spectra for PET particles (a) untreated (b) He treated (10 slm helium flow rate and $30 \mathrm{~min}$ treatment time) and (c) $\mathrm{He} / \mathrm{O}_{2}$ treated (10 slm helium flow rate, $0.05 \mathrm{O}_{2}$ flow rate and 30 min treatment time).

Figure 10 XPS Si 2p spectrum of a silicone particles surface before and after plasma treatment. 

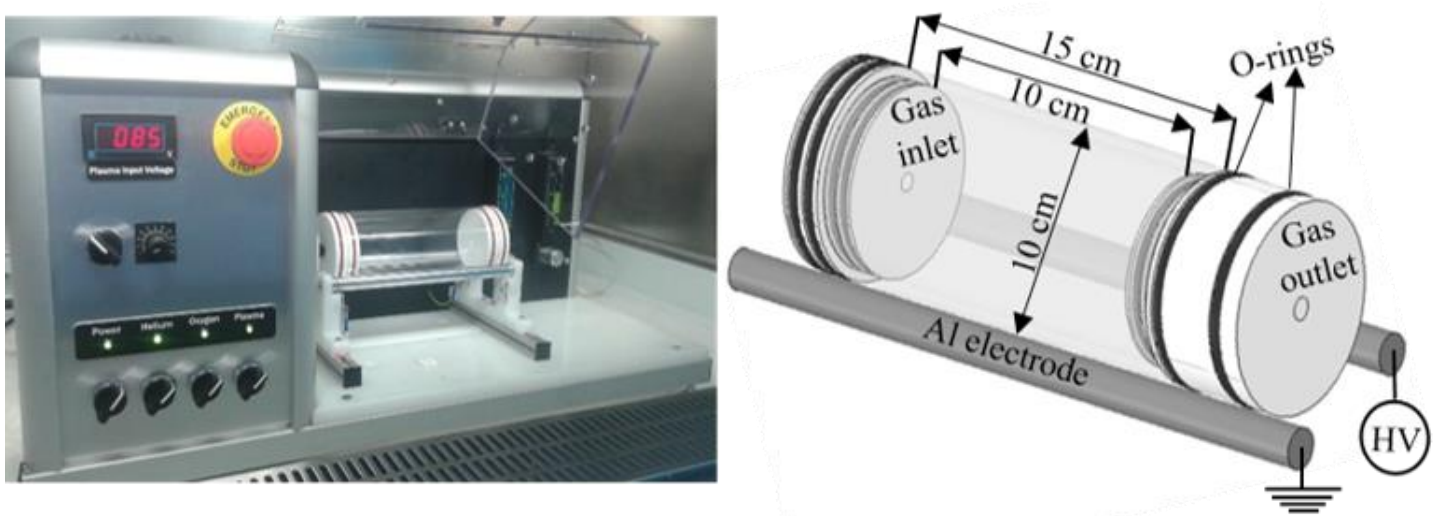

Figure 1: Photograph of the barrel reactor (left) and schematic diagram of the plasma barrel showing a roller arrangement in direct contact with the barrel (right)
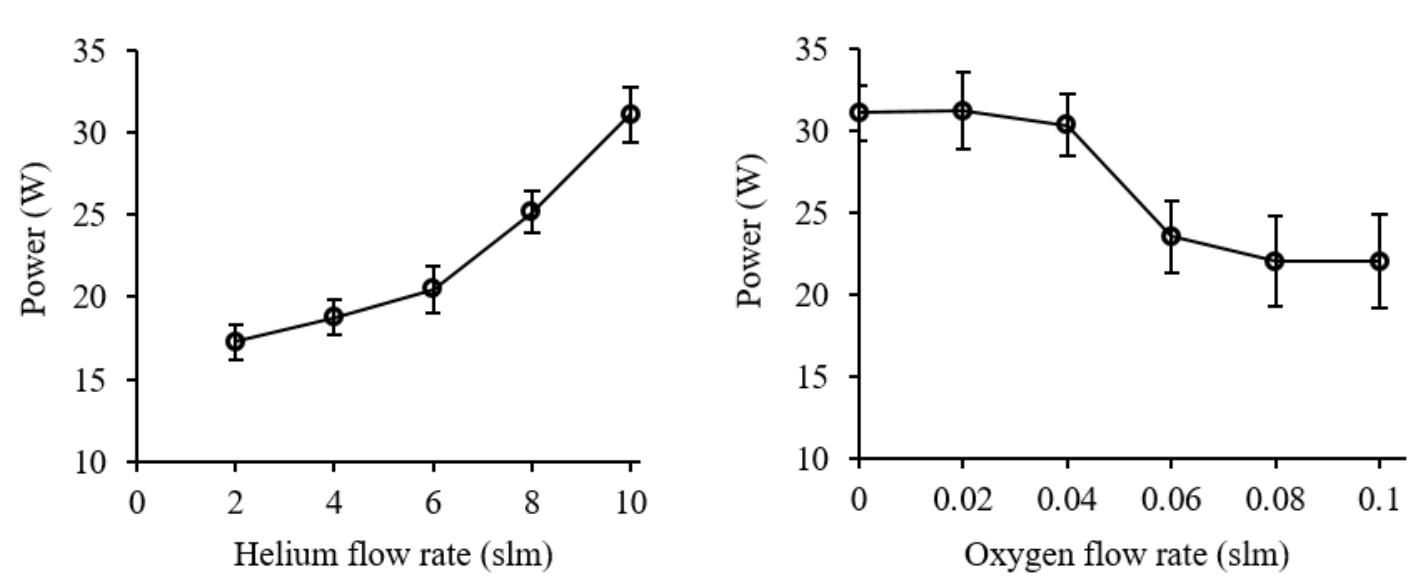

Figure 2: Effect of both helium flow rate(left) and oxygen flow rate (right) on the barrel plasma power

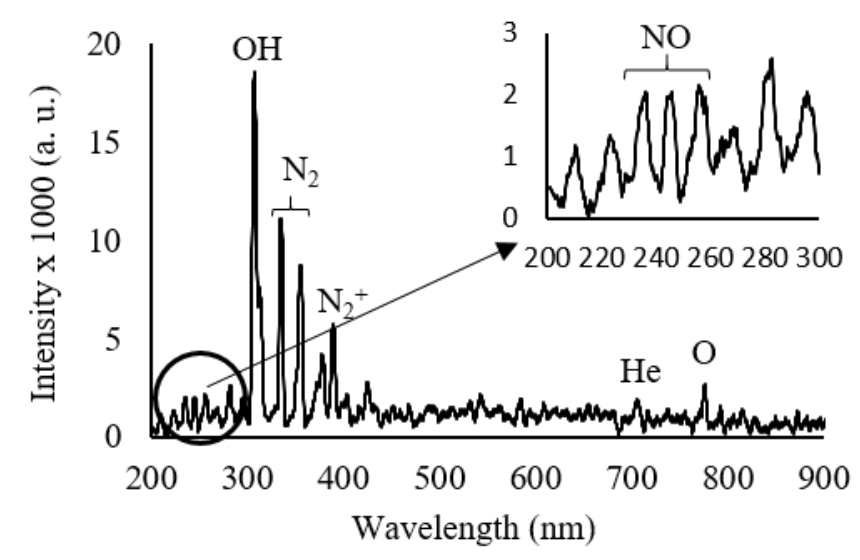

Figure 3: Optical emission spectrum obtained from the barrel reactor 


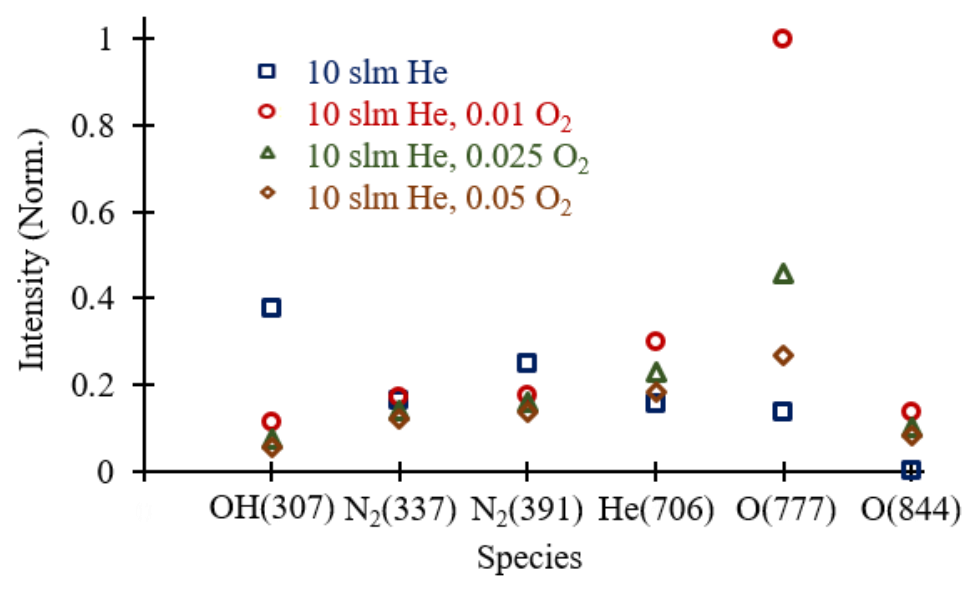

Figure 4: Effect of oxygen flow rate on the plasma species intensities obtained by OES. (He flow rate 10 s/m and voltage 100 V)
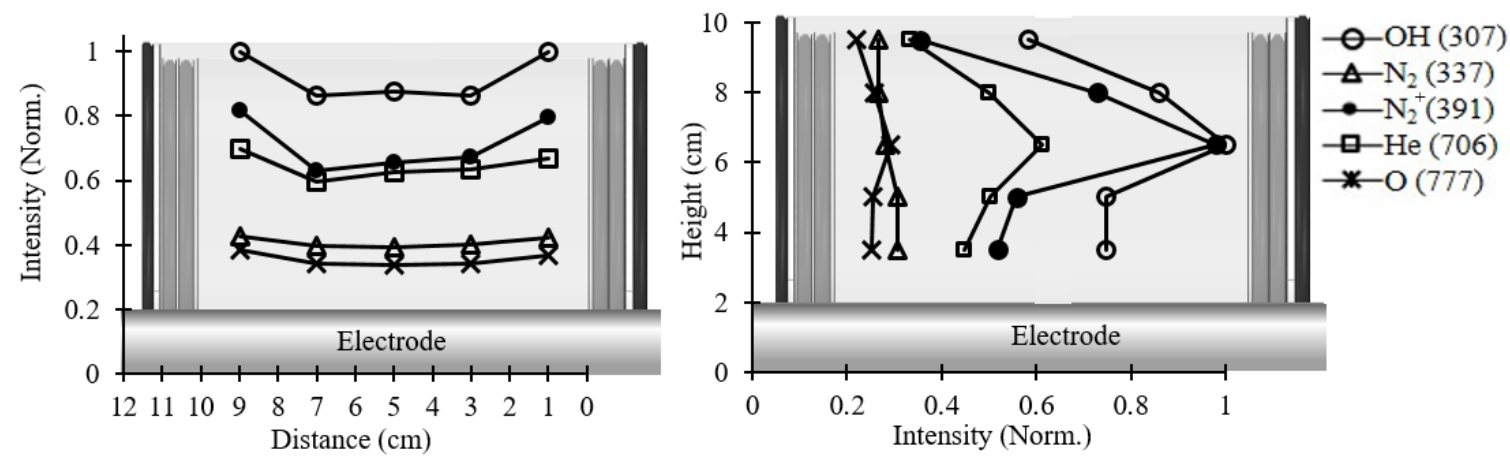

Figure 5: Axial (left) and radial (right) OES spectral distribution within the barrel chamber

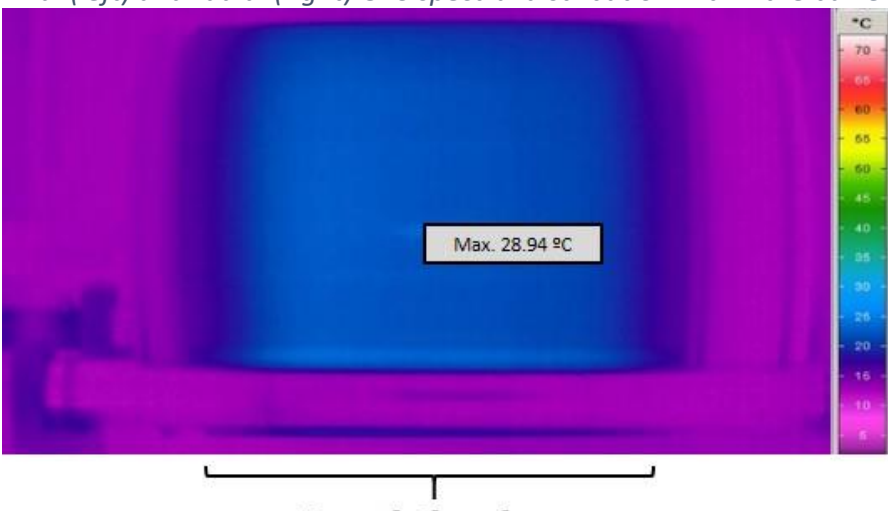

Barrel Chamber

Figure 6: Thermographic image (He flow rate $10 \mathrm{slm}$ and input voltage $100 \mathrm{~V}$ ), the maximum temperature obtained was $28.9 \stackrel{\circ}{\circ}$ 


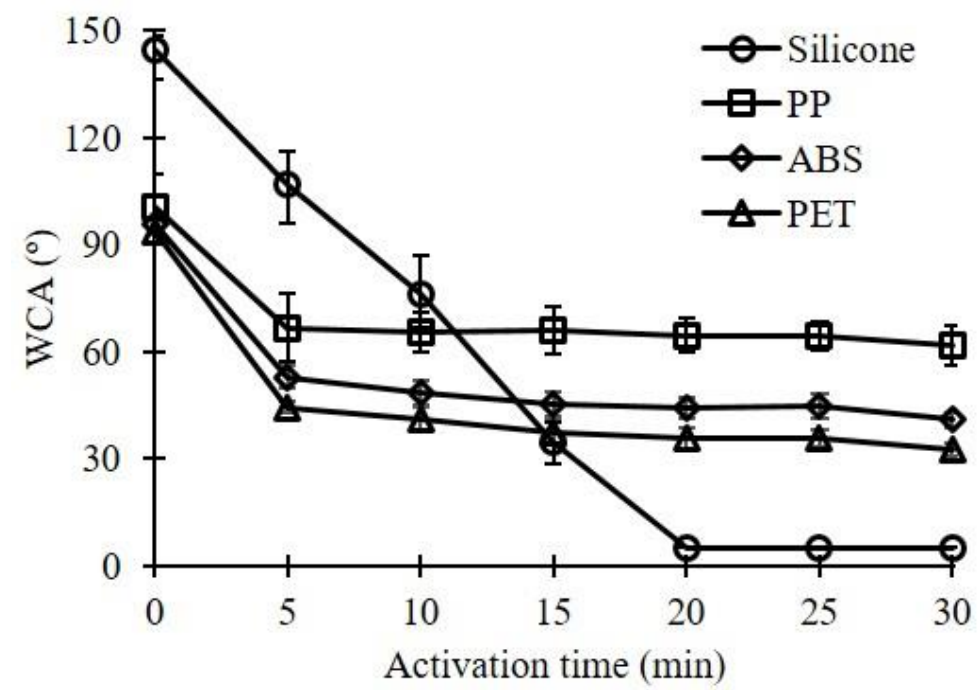

Figure 7: Effect of barrel plasma treatment time on the water contact angle of polymers. Note that for water contact angles of $<5^{\circ}$ no error bars are included, as it is not possible to obtain accurate angle measurements. (Input voltage $100 \mathrm{~V}, \mathrm{He}$ flow rate $10 \mathrm{~s} / \mathrm{m}$ and $\mathrm{O}_{2}$ flow rate $0.05 \mathrm{~s} / \mathrm{m}$ )
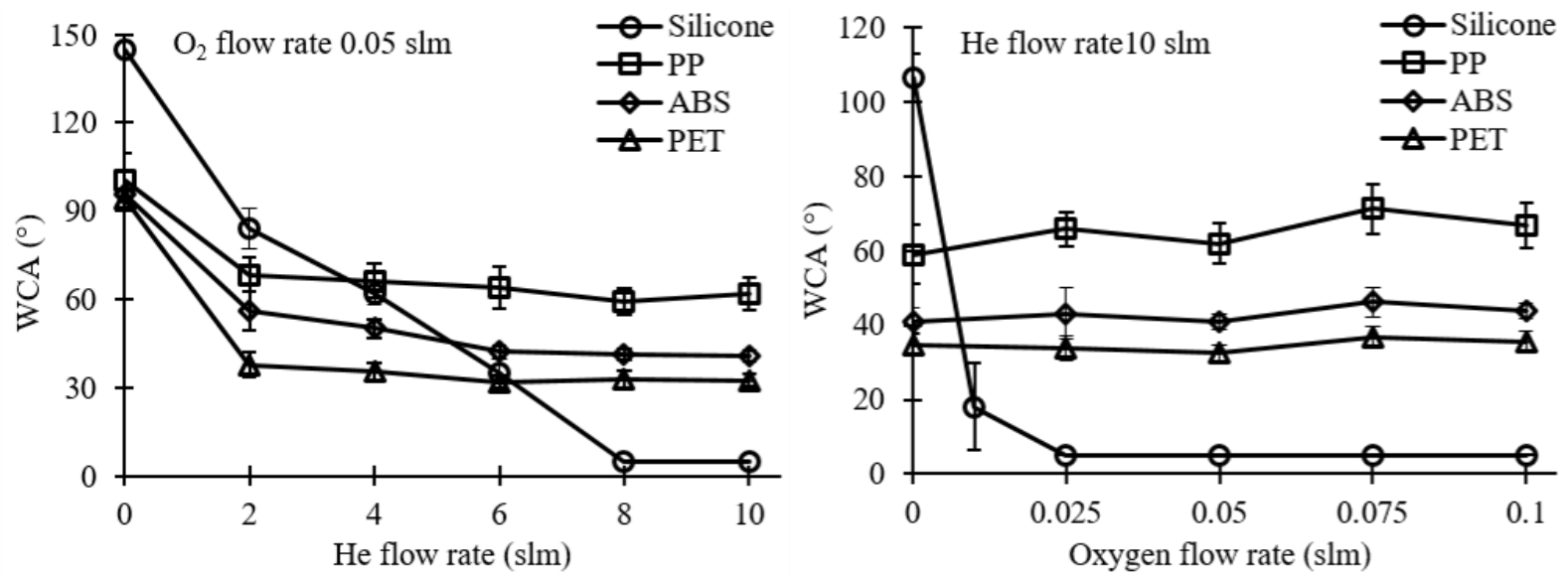

Figure 8: Effect of helium flow rate (left) and oxygen flow rate (right) on the water contact angle of the different polymer particles. (Input voltage $100 \mathrm{~V}$ and activation time $30 \mathrm{~min}$ ). Note that in the case of oxygen flow rate the 0 point is for treatment in a He only plasma. While in the case of He flow rate the 0 point is the WCA obtained before plasma treatment. 


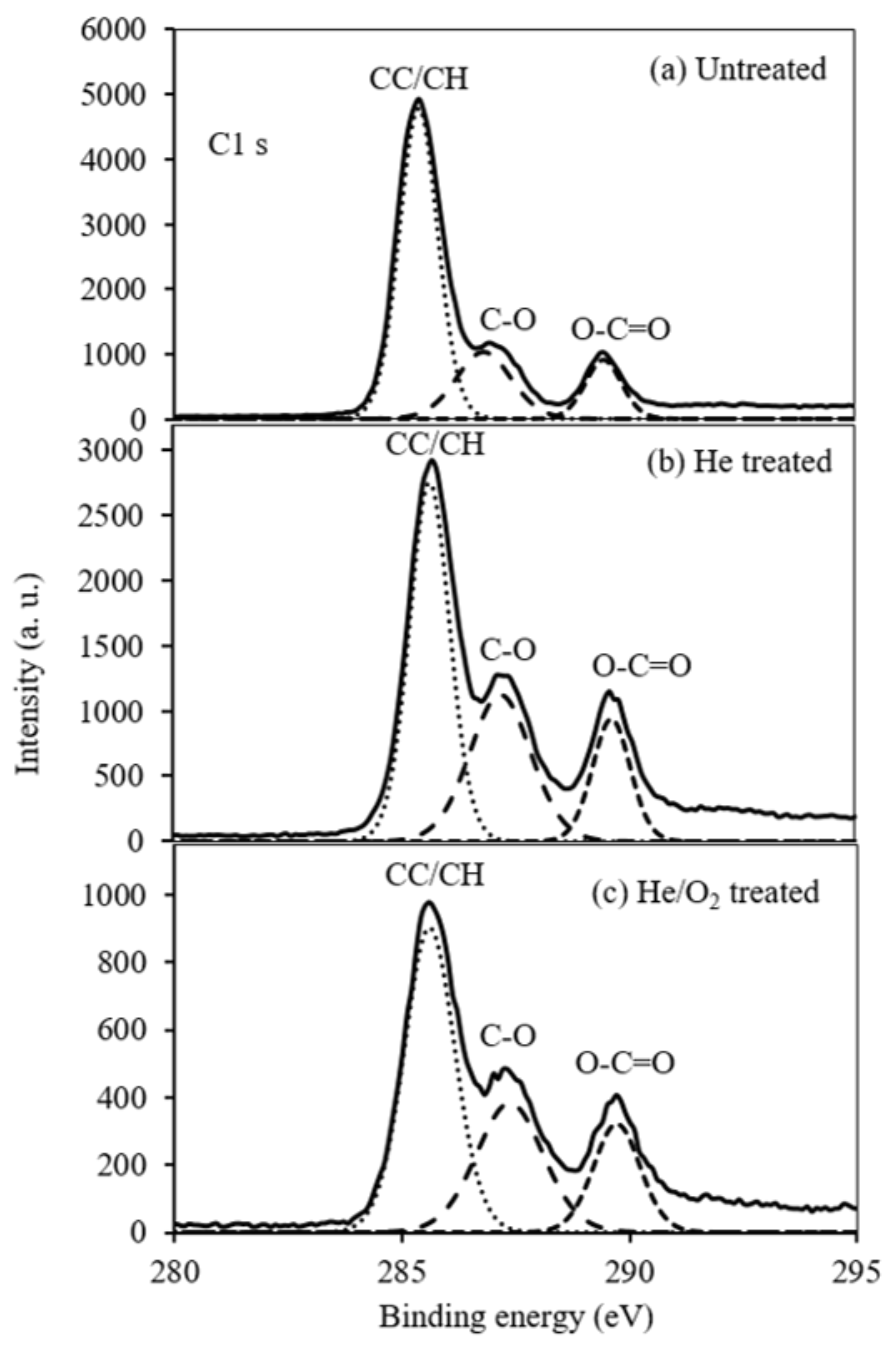

Figure 9: C1s XPS spectra for PET particles (a) untreated (b) He treated (10 s/m helium flow rate and 30 min treatment time) and (c) $\mathrm{He} / \mathrm{O}_{2}$ treated (10 s/m helium flow rate, $0.05 \mathrm{O}_{2}$ flow rate and 30 min treatment time)

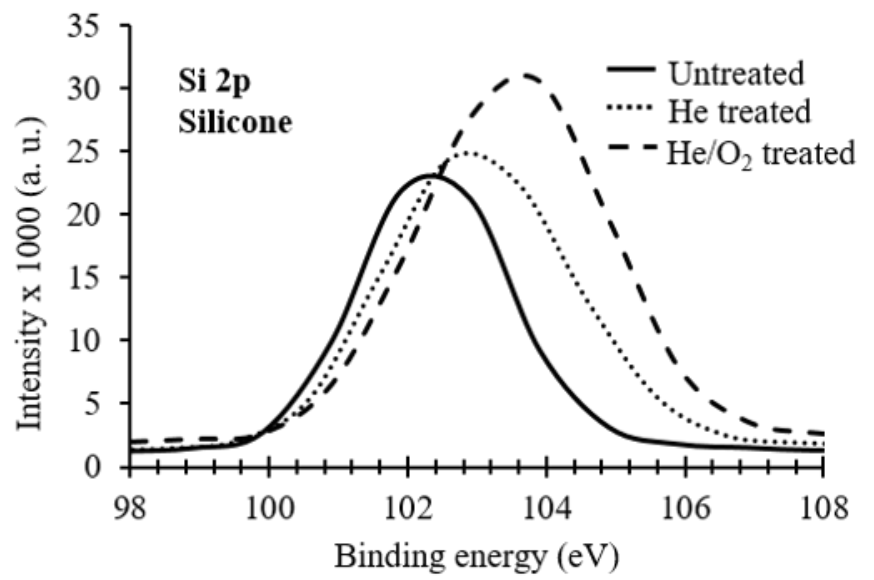

Figure 10: XPS Si $2 p$ spectrum of a silicone particles surface before and after plasma treatment 